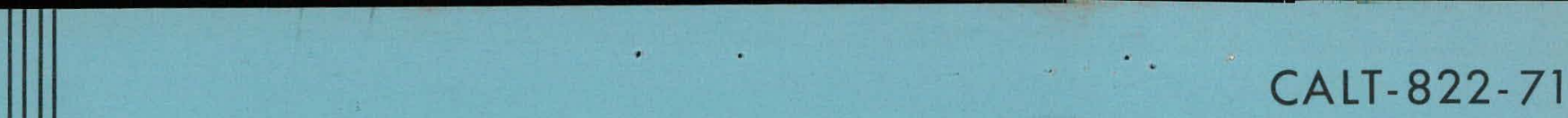

\title{
THE STRUCTURE OF AN AMORPHOUS SUPERCONDUCTOR, LANTHANUM-GOLD
}

\author{
J. Logan
}

MARCH 1975

A REPORT ON RESEARCH CONDUCTED UNDER CONTRACT FOR THE

U.S. ATOMIC ENERGY COMMISSION

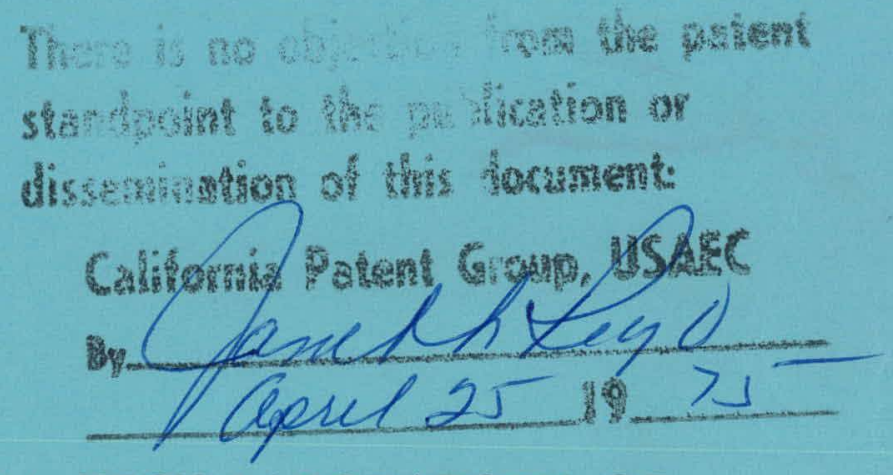

W. M. KECK LABORATORY OF ENGINEERING MATERIALS

CALIFORNIA INSTITUTE OF TECHNOLOGY

PASADENA 


\section{DISCLAIMER}

This report was prepared as an account of work sponsored by an agency of the United States Government. Neither the United States Government nor any agency Thereof, nor any of their employees, makes any warranty, express or implied, or assumes any legal liability or responsibility for the accuracy, completeness, or usefulness of any information, apparatus, product, or process disclosed, or represents that its use would not infringe privately owned rights. Reference herein to any specific commercial product, process, or service by trade name, trademark, manufacturer, or otherwise does not necessarily constitute or imply its endorsement, recommendation, or favoring by the United States Government or any agency thereof. The views and opinions of authors expressed herein do not necessarily state or reflect those of the United States Government or any agency thereof. 


\section{DISCLAIMER}

Portions of this document may be illegible in electronic image products. Images are produced from the best available original document. 


\title{
California Institute of Technology
}

W. M. Keck Laboratory of Engineering Materials

THE STRUCTURE OF AN AMORPHOUS SUPERCONDUCTOR,

\section{LANTHANUM -GOLD}

by

\section{J. Logan}

\begin{abstract}
AEC Research and Development Report No. 62, under Contract No. AT(04-3)-822 Professor Pol Duwez, principal investigator.
\end{abstract}




\section{NOTICE}

This report was prepared as an account of work sponsored by the United States Government. Neither the United States nor the United States Atomic Energy Commission, nor any of their employees, nor any of their contractors, subcontractors, or their employees, makes any warranty, express or implied, or assumes any legal liability or responsibility for the accuracy, completeness or usefulness of any information, apparatus, product or process disclosed, or represents that its use would not infringe privately-owned rights. 


\section{INTRODUCTION}

This note reports a structural study on La ${ }_{80} \mathrm{Au}_{20}$ produced by rapid-quenching from the liquid state. 1 Other amorphous superconductors have been produced by vapor deposition. $2,3,4$ The alloy appears to be an ideal type II superconductor (Ginzburg-Landau parameter $~ 70)(5)$ with a sharp $\left(0.2^{\circ} \mathrm{K}\right)$ transition temperature at $3.5^{\circ} \mathrm{K}$, which indicates the alloy is quite homogeneous on the scale of the coherence length $(\sim 90 \AA)$. The critical current at zero field is $10^{4} \mathrm{amp} / \mathrm{cm}^{2}$, and there is a linear variation of the upper critical field with temperature. The composition range for the amorphous structure is 18 to 26 atomic \% gold.

\section{EXPERIMENT}

The alloy was prepared by induction melting on a silver boat under argon atmosphere. Foils $(60 \mu$ thick) were quenched by the piston and anvil technique. ${ }^{6}$ The density was measured by hydrostatic weighing. 7 The $\mathrm{x}$-ray apparatus, data collection and analysis techniques are described elsewhere. 8,9 It was necessary to mount three foils together in order to intercept the entire $x$-ray beam." During the 4-days of data collection, minor surface oxidation occurred; and after one month, the specimens had disintegrated from oxidation.

Corrections to the data included backround, polarization, multiple scattering, and Compton modified radiation. The data was converted from a rbitrary units into electron units by the high-angle normalization method. 10 The reduced intensity $k i(k)(k=4 \pi \sin \theta / \lambda)$ is shown in 
Figure 1. W(r), Figure 2, is obtained by Fourier transformation,

$$
W(r)=\frac{2 r}{\pi} \int_{0}^{17.4 \AA} k i(k) \sin (k r) \exp \left(-0.01 k^{2}\right) d k
$$

The radial distribution function is, $R D F=4 \pi r^{2} \rho(r)=4 \pi r^{2} \rho_{0}+W(r)$; $\rho_{0}=7.36 \pm 0.03 \mathrm{gm} / \mathrm{cc}$. For a binary alloy

$$
\rho(r)=0.67 \rho_{\mathrm{La}-\mathrm{La}}+1.96 \rho_{\mathrm{La}-\mathrm{Au}}+0.36 \rho_{\mathrm{Au}-\mathrm{Au}}{ }^{\prime}
$$

where the partial density functions, $\rho_{i j}$, are the number of $j$-type atoms per unit volume at distance $r$ from an i-type atom, and the constants are the average weight factors ${ }^{11}$ computed from the atom fractions and dispersion corrected scattering factors of the elements ${ }^{12}$ The first peak in the RDF appears to contain only contributions from ${ }^{\rho} \mathrm{La}-\mathrm{Au}$ and $\rho_{\text {La-La }}$, since the position of the maxima ( 3.33 and $3.75 \pm 0.05 \AA$ ) correspond to the La-Au and La-La distances (3.31, and $3.74 \AA$ ) computed from the Goldschmidt radii. The leading edge of the smaller La-Au peak is approximately Gaussian, and a reflection about an axis at $3.33 \AA$ allows computation of its area. This area was subtracted from the total area, up to the minimum at $4.5 \AA$; to obtain the area under the $p_{\text {La-La }}$ peak. These areas together with the weight factors yield the La-Au coordination number, 2.9, and the La-La coordination number, 8. 1. The estimated error in these values from termination and $k$-dependent errors is $< \pm 0.5$. 


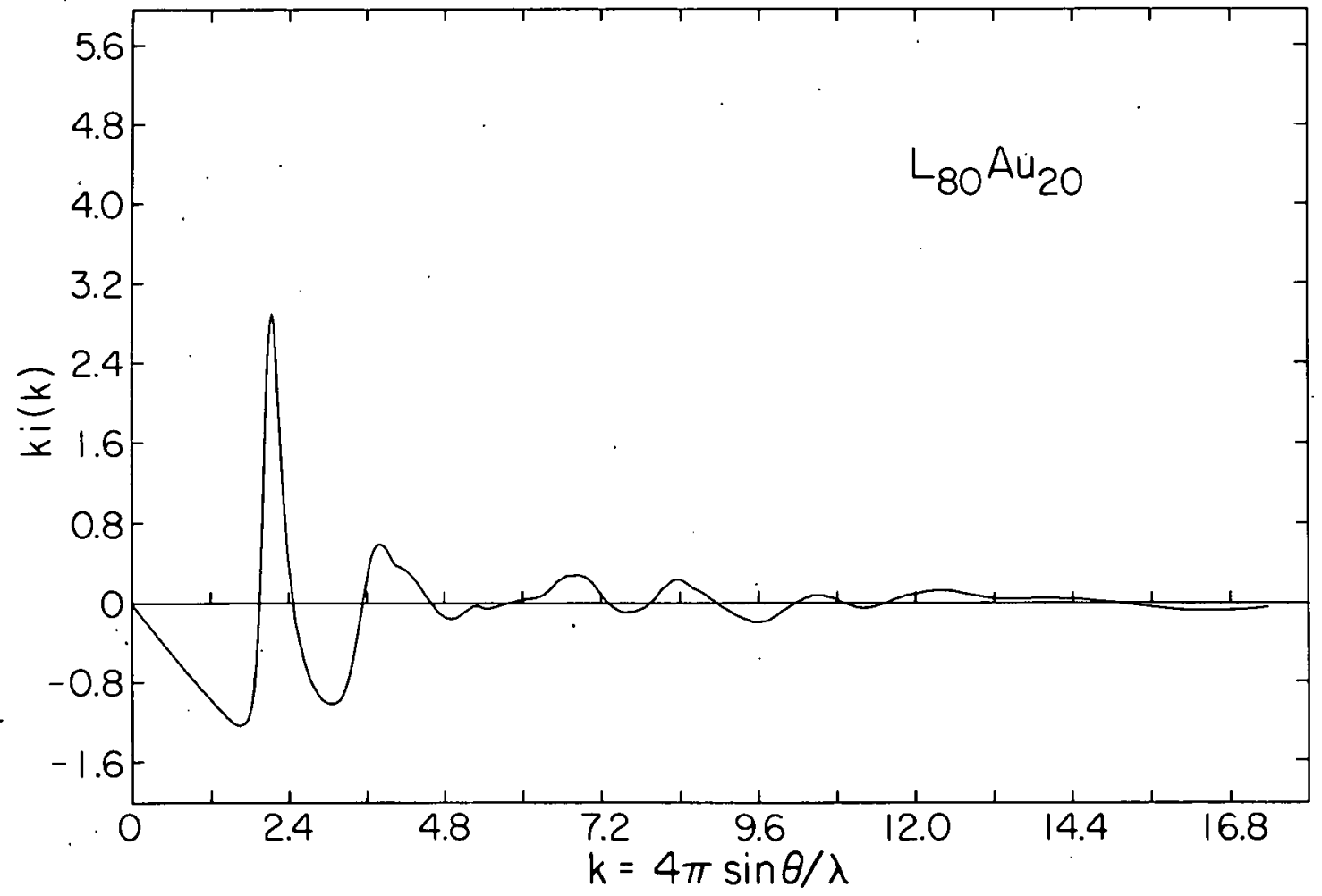

Fig. 1. The reduced intensity ki(k), of amorphous La-Au damped by a factor of $\exp \left(-0.01 \mathrm{k}^{2}\right)$. 
)

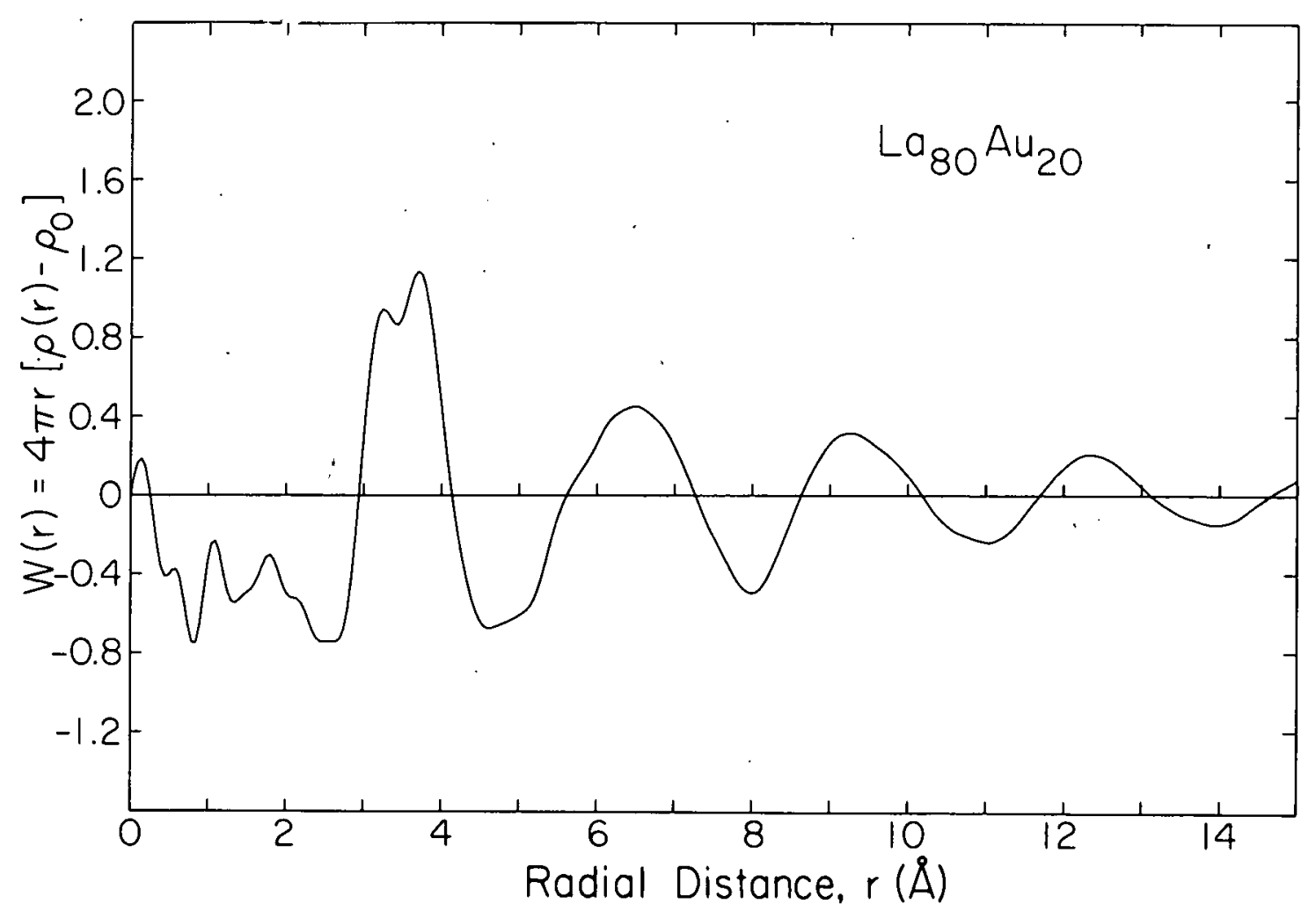

Fig. 2. The function $W(r)$. 


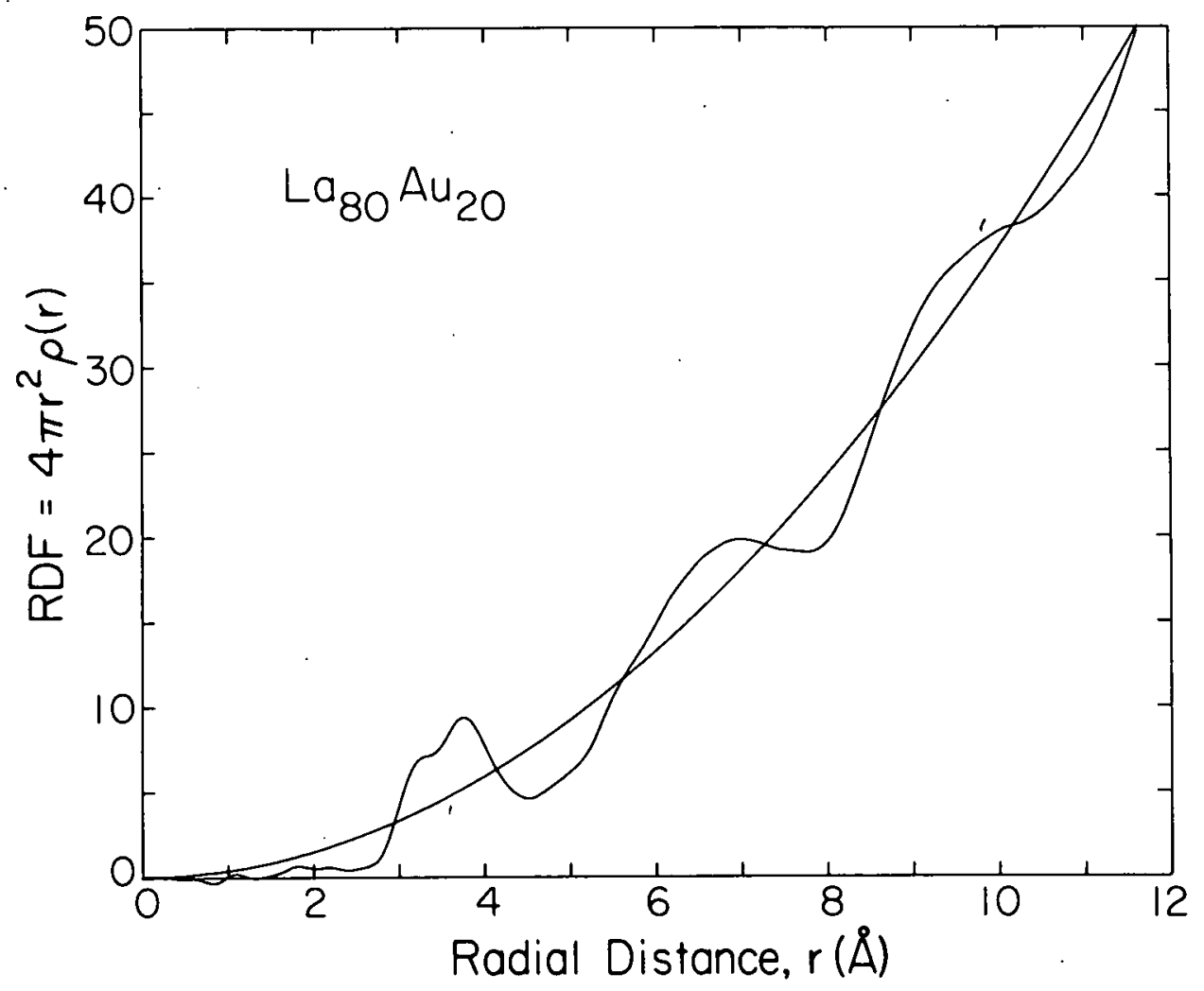

Fig. 3. The radial distribution function. 


\section{DISCUSSION}

Two important features of crystalline $\mathrm{La}_{2} \mathrm{Au}$ (Table I) ${ }^{13}$ are the La-Au distance is, on average, smaller than the La-La distance; and

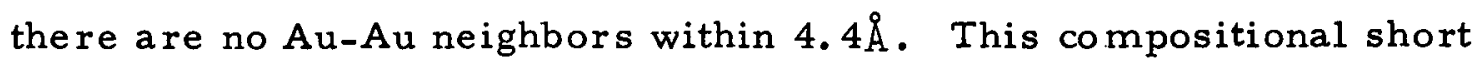
range order appears to be maintained in the glass. The glass has a range of interatomic distances characterized by a full width at half maximum of $0.36 \AA$ for the La-Au peak and $0.68 \AA$ for the La-La peak. This is typical of other glassy systems. ${ }^{14,15}$ Although no pronounced splitting occurs in the second peak of the RDF, it appears to be the superposition of at least two peaks centered at 5.90 and $6.97 \AA$. The lack of definition in these peaks makes the quoted positions only rough estimates. The weak correlation beyond first neighbors is observed in other amorphous rare-earth alloys. 16,17 This suggests either there is no significant order outside the first shell, or the weighted partial density functions combine into a broad second peak; each component representing a well-defined order out to second nearest neighbors. There is some hope for further defining this structure by the method of extended $x$-ray absorption fine structure. 18

Finally, consider the relation between the structure and superconducting properties. The disordered structure implies a short electron mean free path and therefore a short coherence length. 1 Taking another viewpoint, the superconducting properties may provide unique information on the defect structure of the glass. For the glass, the critical current varies smoothly with applied field and demonstrates reversibility with no evidence of flux pinning. This is not observed for the crystal, and flux pinning does occur. ${ }^{5}$ This result suggests that 


\section{TABLE I}

Interatomic Distance and Coordination Number (CN) for crystalline La ${ }_{2} \mathrm{Au}$

The distance is followed in parenthesis by the number of neighbors.

\begin{tabular}{|c|c|c|c|c|}
\hline atom $_{\text {site }}^{\text {nej }}$ & La I & La $\amalg$ & $\mathrm{Au}$ & $\begin{array}{l}\mathrm{CN} \\
(=\text { no. } \mathrm{La}+\text { no. } \mathrm{Au}) \\
\text { within } 4.3 \AA\end{array}$ \\
\hline La I & $3.61(2)$ & $\begin{array}{l}3.54(1), 3.64(2) \\
3.70(2), 3.76(1)\end{array}$ & $\begin{array}{l}3.02(2), 3.11(2) \\
4.42(1)\end{array}$ & $8+4$ \\
\hline La II & $\begin{array}{l}3.54(1), 3.64(2) \\
3.70(2), 3.76(1)\end{array}$ & $4.21(2)$ & $3.28(3), 3.65(2)$ & $8+5$ \\
\hline $\mathrm{Au}$ & $\begin{array}{l}3.02(2), 3.11(2) \\
4.42(1)\end{array}$ & $3.28(3), 3.65(2)$ & $4.46(2), 4.53(2)$ & $9+0$ \\
\hline
\end{tabular}


amorphous La-Au is an ideal type II superconductor and implies that dislocations and other microstructure may not exist in the glass. Flux pinning by dislocations and other substructure is firmly established ${ }^{20}$; however the superconducting properties are often a sensitive function of the cold work and annealing. 21 For this reason, further tests are needed to confirm the ideal type II behavior.

ACKNOWLEDGMENT - This work was supported by the U. S. Atomic Energy Commission. The author wishes to thank Dr. W. Johnson, S. Poon, and Professor Pol Duwez for many helpful discussions. 


\section{REFERENCES}

1. W. L. Johnson, S. J. Poon, and P. Duwez, Phys. Rev. B, Jan., 1975.

2. W. Buckel, and R. Hilsch, Z. Physik, 146, 27, 1956.

3. S. Fujime, J.A.P. (Japan), 5, 764, 1966.

4. M. M. Collver, and R. H. Hammond, Phys. Rev. Lett., 30, 92, 1973.

5. W. L. Johnson, and S. J. Poon, to be published in J. A. P., MarchApril, 1975.

6. P. Duwez, R. H. Willens, R. C. Crewdson, J.A.P., 36, 2267, 1965.

7. J. Logan, Scripta Met., 8, 727, 1974.

8. B. E. Warren, X-Ray Diffraction, Addison Wesley, Reading, Mass., 1969.

9. J. Logan, to be published in Phys. Stat. Solidi (b).

10. N. S. Gingrich, Rev. Mod. Phys., 15, 90, 1943.

11. R. Kaplow, S. L. Strong, and B. L. Averbach, in Local Atomic Arrangements Studied by X-Ray Diffraction, ed. J. B. Cohen and J. E. Hilliard, Gordon and Breach, New York, 1966.

12. D. T. Cromer, and J. T. Waber, Acta Cryst., 18, 17 and 104, 1965.

13. O. D. McMasters, K. A. Gschneider, G. Bruzzone, and A. Palenzona, J. of Less-Common Metals, 25, 135, 1971 .

14. B. C. Giessen, and C. N. J. Wagner, in Liquid Metals, ed. S. Z. Beer, Marcell Dekker, New York, 1972. 
15. G. S. Cargill, to be published in Solid State Physics.

16. G. S. Cargill, AIP Conf. Proc. No. 18, "Magnetism and Magnetic Materials-1973", ed. C. D. Graham, J. J. Rhyne, AIP, New York, p. $631,1974$.

17. G. S. Cargill, and S. Kirkpatrick, to be published.

18. D. E. Sayers, F. W. Lytle, E. A. Stern, J. of Non-Cryst. Solids, $8-10,401,1972$.

19. J. D. Livingston, and H. W. Schadler, Progr. Mater, Sci., 12, 183, 1964.

20. D. Dew-Hughes, Mater. Sci. Eng., 1, 2, 1966. 